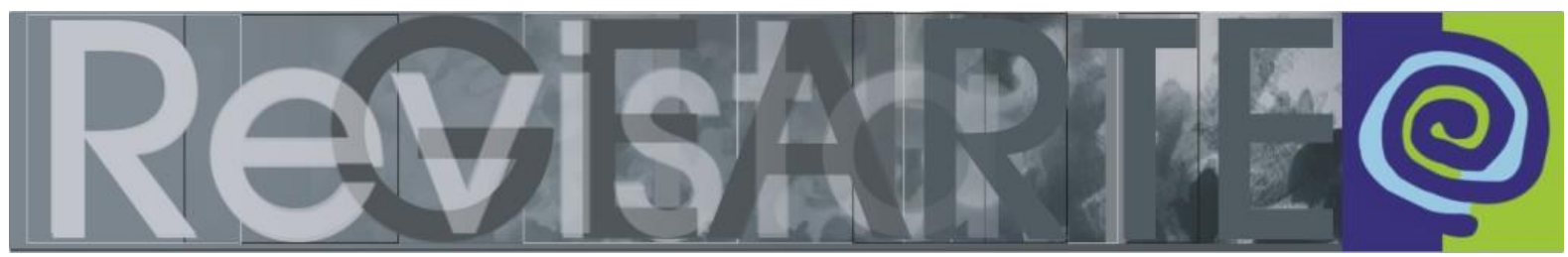

e-ISSN 2357-9854

\title{
Currículo como possibilidade de formação docente em arte: um olhar sobre a rede pública estadual paulista
}

\author{
Maristela Sanches Rodrigues (Instituto Federal de \\ São Paulo — IFSP, Jacareí/SP, Brasil)
}

\begin{abstract}
RESUMO - Currículo como possibilidade de formação docente em arte: um olhar sobre a rede pública estadual paulista - Este texto parte da premissa de que currículos oficiais se constituem como parte das políticas públicas para a educação e que representam possibilidades de formação docente. A partir de pesquisa realizada com professoras/es de arte da rede pública estadual paulista (2012-2016), o texto procura refletir sobre encontros e desencontros entre as concepções formativas dessas/es professoras/es e as concepções trazidas pelo currículo de arte oficial de São Paulo (2008atual). Concepções de arte, de acesso à arte, de ensino de arte e de currículo de Arte, reveladas nas conversas com 18 professoras/es de Arte, provocaram reflexões quanto à relevância de um cuidadoso trabalho de formação docente para atuação com um currículo, formação essa que permita às/aos docentes identificar, compreender, desconstruir e reconstruir suas próprias concepções formativas na relação com o currículo, de maneira a nutrir e sustentar suas escolhas para o ensino/aprendizagem da arte que consideram desejável e/ou imprescindível a seus contextos escolares.
\end{abstract}

PALAVRAS-CHAVE

Formação docente. Currículo de Arte. Concepções formativas.

ABSTRACT - Curriculum as a possibility of teacher training in the arts: a look over the state public schools - This text is based on the premise that official curricula are part of public policies for education and represent possibilities of teacher's formation. From the research carried out with art teachers of Sao Paulo's state public network (2012 - 2016), the text seeks to reflect over meetings and disagreements between these teachers' formative conceptions and the conceptions brought by Sao Paulo's official art curriculum (2008 - current). Conceptions of art, access to art, art teaching and art curriculum, revealed in the conversations with fifteen art teachers, led to reflections on the relevance of a careful work of teacher formation to act with a curriculum, formation which allows the teachers to identify, understand, deconstruct and rebuild their own formative conceptions in the relation to the curriculum, in way to nourish and sustain their choices to the teaching/learning of art that they consider desirable and/or indispensable to their school contexts.

KEYWORDS

Teacher training. Art Curriculum. Formative conceptions.

... nada de novo há / no rugir das tempestades./ Não estamos alegres, / é certo, / mas também por que razão / haveríamos de ficar tristes? / O mar da história / é agitado. / As ameaças / e as guerras / havemos de atravessá-las, / rompê-las ao meio, / cortando-as / como uma quilha / corta as ondas. Vladimir Maiakóvski

Nada de novo há neste texto...

Tampouco nele haverá o esperançoso frescor revolucionário do poeta russo... 
Quando as políticas públicas se tornam tempestades sobre nossas cabeças, atravessá-las ou rompê-las requer mais do que afiadas quilhas cortantes, requer intimidade com as ondas...

$\mathrm{Na}$ intimidade há algo de proximidade, de familiaridade, de conhecimento, mas também há algo secreto, velado, profundo... Intimidade demanda confiança... Confiança se achega ao conhecimento... Conhecimento perceptivo, intuitivo, afetivo, sensível, cognitivo...

Este texto busca tratar de intimidade, confiança e conhecimento no campo da formação de professoras/es de arte a partir de políticas públicas, mais especificamente de currículos oficiais. Meu viés não é o de uma abordagem direta sobre as recentes tempestades no campo da educação brasileira. Na contramão das intempéries, busco ancoragem na intimidade das concepções formativas de cada professor/a de Arte a partir de tesouros e escombros oriundos das tais e tantas tempestades...

Entre os anos de 2012 e 2016 realizei uma pesquisa de doutorado no Instituto de Artes da UNESP, em São Paulo, buscando compreender como estava se dando o envolvimento das/os professoras/es de Arte da rede pública estadual paulista com o Currículo ${ }^{1}$ oficial de Arte. Meu olhar voltou-se para as concepções formativas dessas/es professoras/es - concepções de arte, acesso à arte, ensino de arte e currículo de Arte - e suas possíveis relações com as mesmas concepções, oriundas do Currículo de Arte.

Para tanto, entrevistei ${ }^{2} 15$ professoras/es de Arte em exercício em diferentes Diretorias de Ensino, geograficamente dispersas pelo estado de São Paulo. As/os professoras/es atuavam em cidades de distintos portes, sendo que na ocasião - entre os anos de 2012 e 2013 - a menor cidade contava com cerca de pouco mais que três

\footnotetext{
1 A grafia da inicial maiúscula em Currículo de Arte oficial de SP visa diferenciá-lo de currículos genéricos.

2 As entrevistas semiestruturadas previstas inicialmente transformaram-se em conversas entre pares, cuja duração mínima foi de cerca de uma hora e trinta minutos e a duração máxima foi de cerca de quatro horas.
} 
mil habitantes - Álvares Florence - e a maior cidade - São Paulo capital - contava com cerca de 11 milhões de habitantes.

No ano de 2008 foi criada uma Proposta Curricular do Estado de São Paulo para o Ensino Fundamental II e para o Ensino Médio (Resolução SE n. 76/2008), unificando o currículo das escolas públicas da rede estadual paulista e oficializando, em 2010, o Currículo do Estado de São Paulo - atualizado por uma segunda edição em 2013. O Currículo chegou às escolas em 2008 através da Revista do Professorcadernos de orientações relacionadas ao desenvolvimento das competências leitora, escritora e matemática, dirigidos às/aos docentes, e elaborados com base nos resultados do SARESP/2005 e, também, através do Jornal do Aluno - material utilizado pelas/os alunas/os e relacionado à Revista do Professor - com o objetivo de retomar aprendizagens necessárias à implantação do novo currículo.

Posteriormente, mas ainda em 2008, chegou às escolas o Caderno do Professor, esse sim, direcionado para cada disciplina do Currículo. No segundo semestre de 2008 foi oferecido, às/aos professoras/es ingressantes na rede, um curso a distância - A Rede Aprende com a Rede - que contava com vídeo aulas e videoconferências com as/os autoras/es dos Cadernos, visando contribuir com a implementação do Currículo.

Em 2009 o Currículo chegou às escolas, tanto pelo Caderno do Professor agora reformulado -, quanto pelo Caderno do Aluno. Além desses materiais, em 2010 foi lançado o Caderno do Gestor e o Currículo do Estado de São Paulo. Ainda em 2008, o curso semipresencial Tão perto, Tão longe - oferecido, em duas edições, pela Fundação Bienal de São Paulo e voltado às/aos professoras/es de Arte da rede pública - buscou também dialogar com o Currículo e contribuir com a discussão das/os arte/educadoras/es sobre arte contemporânea.

No ano de 2013 o Caderno do Aluno do componente Arte não foi distribuído para as escolas por estar passando por revisões. As/os professoras/es contavam com seus cadernos para dar continuidade às proposições curriculares. 
A concepção geral do currículo paulista esteve sob a responsabilidade dos seguintes profissionais: Guiomar Namo de Mello, Lino de Macedo, Luís Carlos de Menezes, Maria Inês Fini e Ruy Berger, sendo que Maria Inês Fini foi, também, a coordenadora geral. A coordenação técnica do Currículo coube à Coordenadoria de Estudos e Normas Pedagógicas - CENP - uma dentre as várias coordenadorias que estruturavam a Secretaria de Educação do Estado de São Paulo, extinta em 2013. O Currículo de Arte, por sua vez, esteve sob a coordenação das professoras/pesquisadoras, Mirian Celeste Martins e Gisa Picosque.

O texto de introdução ao Currículo paulista - Apresentação do Currículo do Estado de São Paulo (2010, p. 7-24) - subdividido em: Uma educação à altura dos desafios contemporâneos e Princípios para um currículo comprometido, apresenta duas concepções que me foram particularmente caras e sobre as quais teço algumas considerações. Trata-se das concepções de autonomia e de acesso e inclusão, ambas presentes e sustentadas no texto curricular por algumas palavras e/ou expressões.

O que primeiramente me chamou a atenção no texto curricular introdutório foram alguns verbos que remetem aos objetivos do Currículo, como: apoiar, fomentar, garantir, contribuir, orientar e assegurar. Tais palavras remetem à ideia de que esse Currículo possa ser um subsídio, um apoio, um recurso, um contributo, uma referência, ou seja, uma proposição para favorecer a atuação docente e, por que não dizer?: a formação! Um instrumento que suscite e viabilize a autonomia e a criatividade do/a professor/a dentro de seu contexto específico de formação e de atuação.

A despeito de entender que a apropriação do Currículo se dá no lócus escolar e que, portanto, a interpretação que dele será feita, em cada escola, dependerá das múltiplas variáveis que determinam a educação escolar, intrigava-me o distanciamento que parecia haver, para não dizer a contradição, entre dois discursos que, a meu ver, necessitariam estar em maior sintonia.

Se a intenção era de apoiar e subsidiar, entendo que não bastava lançar o Currículo na rede escolar. Uma cuidadosa implantação prescinde de um programa de formação continuada de todas/os as/os professoras/es - e não apenas das/os 
ingressantes - para que essas/es pudessem compreender e se apropriar das concepções do novo currículo, bem como, uma melhoria e/ou a adaptação da estrutura escolar se fazia necessária para viabilizar a nova prática curricular.

Para que as/os professoras/es pudessem viabilizar, fomentar, estimular e possibilitar aos seus estudantes o desenvolvimento de autonomia, conforme preconiza o texto curricular - entendo que as/os professoras/es também deveriam lograr a autonomia, sobre a qual o currículo refere-se assim:

Construir identidade, agir com autonomia e em relação ao outro, bem como incorporar a diversidade, são as bases para a construção de valores de pertencimento e de responsabilidade, essenciais para a inserção cidadã nas dimensões sociais e produtivas. (SÃO PAULO, 2010, p. 10).

Volto-me, neste trecho, à forma como estão inter-relacionadas as palavras identidade e autonomia, pertencimento e responsabilidade, pois o Currículo paulista é bastante prescritivo, chegando a propor atividades para cada aula. Como construir identidade e autonomia a partir de um currículo tão prescritivo? Além disso, as/os professoras/es paulistas não foram convidadas/os a participar da elaboração do Currículo, tampouco, aquelas/es que não eram ingressantes contaram com formação específica para atuar com o Currículo. Como gerar pertencimento e responsabilidade, então? Apropriação, resistência, transgressão?

Em uma perspectiva pós-estruturalista, sob a inspiração de Elizabeth Macedo e Alice Casimiro Lopes (2008), passei a olhar para esse contexto de maneira a entender que os sujeitos se constituem na ação política, ou seja, que elas/eles não preexistem à ação política, eles se constroem em meio à atuação política, o que não significa que não existam poderes que suplantam outros e que, muitas vezes, os sujeitos têm suas possibilidades limitadas; significa dizer que nenhuma dominação cultural é tão poderosa a ponto de minar os sistemas locais e que, também, nenhum sistema local fica imune ao colonialismo. Ainda:

[...] como lidar com os limites impostos pela estrutura social, sem determinismos e sem desesperanças que nos levem ao imobilismo, à incapacidade de ação social de mudança (agência)? Como teorizar, por sua vez, a possibilidade de o sujeito atuar imaginando e produzindo uma transformação social, sem voluntarismos, visões românticas e dependentes 
de conceitos fixos e estruturados como consciência de si e do mundo? (MACEDO; LOPES, 2011, p. 181).

Em verdade, esse olhar só me foi possível após o término das entrevistas e mediante a percepção de que, a despeito de toda a prescrição do Currículo de Arte e do pouco cuidado com a formação das/os professoras/es, havia interstícios para a ação política docente e é aí que ancoro meu texto. Toda ação política é guiada por concepções formativas e se não investimos na formação docente, as ações políticas possíveis às/os professoras/es a partir de suas próprias concepções formativas pode não ser condizente com aquilo que as políticas públicas almejam.

Ou seja, quando afirmei no início deste texto que para lidar com as tempestades é preciso mais do que quilhas afiadas; é preciso intimidade com as ondas, era disso que eu falava: para lidar com proposições curriculares em cuja elaboração não houve pertencimento, é preciso saber de quais concepções formativas partem as/os professoras/es e como poderão transformar e negociar tais concepções com aquelas propostas pelo currículo oficial. Identificar, compreender e relacionar suas concepções com as do Currículo, me pareceu ser um caminho promissor para futuras escolhas autorais e significativas para cada contingência escolar vivida pelas/os professoras/es de Arte no estado de SP, quer fosse na pequena Álvares Florence, quer fosse na grande São Paulo.

Para tornar este discurso mais concreto, trarei algumas falas de professoras/es de Arte do estado de SP, para que se possa ter a dimensão do quanto o texto curricular é potencialmente formador. Para tanto, organizarei as falas segundo as concepções que elas abarcam e, assim como na tese que nasceu desta pesquisa, as falas não serão seguidas de análises; elas são apresentadas como as possibilidades de cada professor/a lidar com as questões suscitadas pelo envolvimento com o Currículo.

Alimentando nossas reflexões, as falas das/os professoras/es - a seguir - nos possibilitam, acima de tudo, compreender que currículos funcionam como instrumentos políticos de formação. Portanto, há que se cuidar dos rumos que desejamos conferir às nossas ações políticas como arte/educadoras/es e dos rumos que entendemos que as políticas públicas educacionais devem e podem tomar para 
que o ensino/aprendizagem da arte na escola possa garantir a potente ação transformadora e humanizadora da arte. Cultivar intimidade com nossas concepções formativas pode fortalecer nossas ações políticas no necessário enfrentamento das tempestades...

\title{
Concepções de arte
}

\begin{abstract}
Arte seria um dos únicos meios de libertação de um aluno, no caso, de liberdade de pensamento, escolha, flexibilidade de pensar, autonomia, liberdade! Olha, não me peça para explicar, é isso! [...] está muito pesado para a arte com esse fim que eu enxerguei, por que matemática, português, geografia são levadas mais a sério! [...] o próprio corpo do aluno na aula de matemática muda, a tensão é outra e quando chega na aula de arte, que o aluno desde a 1‥ série está vindo com uma arte que não é a libertadora, na minha opinião, ele confunde essa que se propõe libertadora, então, ele não tem um pré-requisito para receber isso tudo! [...] para os conteúdos do Ensino Médio do Currículo e o Ensino Médio que eu estou vendo na realidade, eles estão super imaturos, principalmente para dança, expressão corporal... Por que não existe na escola, não tem estudo! (Professora PIE)

[...] eu não acho que arte serve para ou tem que servir para o aluno ficar mais comportado ou saber se emocionar com... não! A arte é a arte, ponto! Ela em si já se justifica! [...] mas eu acho que ele tem que saber que existem vários caminhos para ele seguir ali, sabe? [...] Repertório, essa palavra não pode fugir da minha boca! [...] Eu acho que a arte, ao contrário do que muitos pensam, a arte se justifica por si, a arte não serve para nada, não serve para outra coisa, não serve para se concentrar e aprender matemática ou qualquer coisa, ela é a expressão soberana do ser humano! A gente como educador está formando público para nossa própria área, quer dizer, a gente tem que correr atrás de fazer a pessoa se interessar para ver se muda essa visão! Se eu não dou repertório para essa pessoa, eu estou formando um público muito específico! (Professora BPL)
\end{abstract}

Essas e muitas outras concepções de arte estiveram presentes nas minhas conversas com as/os professoras/s de Arte. Pude ouvi-las/os dizer que: a arte é a expressão soberana do ser humano e que, por isso, seu ensino se justifica; a arte trabalha a sensibilidade, a intuição, a criatividade, a expressão e a emoção, para que não nos tornemos robôs; a arte abre o pensamento e leva a novas formas de compreender o mundo; a arte possibilita o autoconhecimento e reforça a autoestima; a arte não é apenas sentimento e emoção, ela é também processo criativo e desperta o pensamento reflexivo; a arte liberta as/os alunas/os, pois torna o pensamento mais flexível e desenvolve autonomia; a arte é pensada hoje como linguagem, como forma de simbolizar e metaforizar o mundo; a arte passa pelo afeto, mas passa também pelo pensamento, pela reflexão e não estamos mais no laissez-faire, saímos desse extremo... 
Múltiplas concepções de arte constituem-nos como arte/educadoras/as e se transformam no envolvimento com os currículos. Conversar sobre essas concepções é uma ação política que alimenta nossas reflexões, nossos questionamentos e ampliam nossas escolhas... Políticas públicas podem, devem e/ou desejam se comprometer com nossas reflexões e escolhas?

\title{
Concepções de acesso à arte
}

\begin{abstract}
[...] se a escola não abraça, se você não tem uma gestão que te apoia, você não consegue o ônibus, não consegue a parceria com os pais, então, tem toda uma relação, da comunidade escolar, de entender que isso faz parte dessa formação do jovem! Quando eu penso nesse Currículo, ele tem, por exemplo, situações e proposições de aprendizagem que pedem para o aluno pesquisar um museu [...]. Nós não temos museu na cidade, nós não temos sequer um museu histórico, não temos! Nós temos uma cidade vizinha, que é Assis, que fica a $12 \mathrm{~km}$ que é uma possibilidade, [...] mas a maioria dos alunos trabalha com os pais em sítio, outros fazem cursos técnicos, então, eles também não têm a possibilidade de ir no horário de contra turno, então [...] qual é a outra opção? A opção é a gente ir junto, a gente cria oportunidade [...]. Quando tudo não dá, tem a outra opção que é a internet, [...] mas aí a gente se depara com outro problema, na minha escola, o Acessa Escola não funciona de manhã por que não tem nenhum aluno que passou na prova para trabalhar de manhã [...] não podemos fazer pesquisas individuais de manhã, então a gente traz o data show, o seu computador, a sua internet porque o roteador do Estado também quase nunca funciona! [...] ônibus de linha que passa aqui e vai para Assis, a Diretoria de Ensino não autoriza porque não tem seguro [...] então, vamos fretar um ônibus de Cândido Mota a Assis, uns $R \$ 700,00$, aí você tem um movimento da escola, faz a rifa ou os alunos pagam ou você faz isso ou você se inscreve no PRODESC e aí uma parte da verba você usa para isso... Aí, você cria a oportunidade! [...] é um movimento cansativo! [...] as situações de aprendizagem propostas no Caderno do Aluno poderiam ter sido pensadas de uma maneira que elas pudessem também olhar para aquela cidade do interior que não tem nada disso por que, às vezes, os nossos alunos, eles também têm ânsia de conhecimento, tanto quanto os alunos de uma capital ou até mais! E aí eles perguntam, "Professora, o que é uma Pinacoteca?", como você vai explicar se você não leva? Você pode trazer, você pode mostrar, mas não é a mesma coisa, não é! (Professora CMA)
\end{abstract}

$\mathrm{Na}$ escola pública a arte é muito distante do público em geral, eles acreditam que arte ainda é aquela ideia elitizada, no pedestal, aquela aura [...] por eu trabalhar nesses meios, eu sempre trago a programação e eles perguntam: "Mas a gente pode ir?", "Mas a gente não tem roupa!" [...] eles acham que não é para eles, a nossa clientela pensa que só o que a grande mídia traz é para eles, fora disso, há um reconhecimento de que existe, mas não existe uma aceitação. [...] Em Araraquara eu acho que isso é muito reforçado [...] existem as oficinas culturais nos bairros e o que a gente vê? O hip-hop, o grafite, entendeu? [...] Sempre mais do mesmo! Vamos fazer um festival para o povão, vem Anita, os sertanejos, um encontro de rap, o grafite, entendeu? As outras linguagens vão para o teatro e tem que pagar [...] $\mathrm{E}$ tem que ir bem vestido e pegar ônibus. No bairro a prefeitura leva, mas leva a cultura de massa. Cria-se uma barreira, inclusive pelas esferas que poderiam trabalhar em parceria para modificar isso! Os professores de arte, a grande maioria, também acha isso e não questiona, não busca, não vai, não entende que aquilo é para ele, ele nem sabe que aquilo é para ele! (Professora AQF)

Muitas e muitas vezes ouvi das/os professoras/es que o Currículo de Arte paulista foi desenvolvido na e para a cidade de São Paulo e que o interior do estado não tinha acesso a muito do que ele propunha, que muitas/os alunas/os não tinham 
e/ou nunca teriam como conhecer e compreender melhor a arte que o Currículo enfatizava. Para meu espanto, quando entrevistei professoras/es em cidades próximas a São Paulo - São Bernardo do Campo e Guarulhos - e posteriormente na própria São Paulo, ouvi o mesmo discurso da falta de acesso. E mais, as mesmas professoras afirmavam que o conteúdo de história da arte que ausentou-se do Currículo era imprescindível para que os estudantes pudessem compreender a arte de hoje - predominante no Currículo - no entanto, referiam-se a uma história da arte europeia - em grande parte - a qual, do ponto de vista da vivência e da experiência presencial é ainda mais distante e inacessível para a grande maioria dos estudantes.

Não seria interessante ter estas conversas em nossos horários de formação pedagógica nas escolas ou diretorias de ensino? Como arte/educadoras/es, não seria interessante conversarmos sobre descolonização/decolonização? Políticas públicas podem, devem e/ou desejam se comprometer com formações docentes descolonizadoras/decolonizadoras?

\section{Concepções de ensino de arte}

No Estado de São Paulo [...] eu tenho que falar que, infelizmente, antes desse Currículo que está em vigor nós tínhamos o ensino de arte subtendido como navio à deriva, barco sem vela em alto-mar, faça o que você bem entender! [...] Vamos fazer capa, vamos colar coisas para decorar a escola, fazer bandeirinhas e coisas assim, então, essa era a grande função da arte, ou seja, vamos acalmar os alunos na aula de arte que daqui a pouco tem a matemática, então, isso acompanha o desprezo e tem a parte que eu acho mais triste, nós nos acomodamos a isso! [...] você não tem na graduação a discussão da estética, a discussão das inter-relações, a dialogia, você não encontra isso na graduação, ou seja, a graduação transforma o ensino de arte realmente num souvenir da escola, numa perfumaria, aqueles professores que se achavam mais inteligentes trabalhavam com história da arte. [...] nós tivemos essa luta, quando eu peguei o Currículo, quando eu vim a compreender o Currículo... (Professor PDF)

As referências eram a história da arte mesmo! A grande referência era o livro da Maria Heloísa Ferraz e da Felisminda Fusari, o Arte na Educação Escolar, por que lá tem uma proposição de curso de ensino de arte [...] ele traz um começo bacana com a retrospectiva das tendências pedagógicas, no segundo momento, ele vai falar do compromisso de ser professor de arte [...] e a questão dos fundamentos estéticos e dos fundamentos artísticos. Depois disso, ela tinha um viés, obviamente que ainda era na história da arte, mas tinha uma proposta! [...] aí, é óbvio, você vai buscar os livros de história da arte, vai construir um caminho [...] Os PCN tiveram um espaço quando trouxemos as outras linguagens. [...] eu me lembro de buscar na Graça Proença, que particularmente não é referência de história da arte, mas enfim, buscar uma linearidade [...] os PCN entraram muito menos para a área das artes visuais, mas muito mais para contribuir com a questão da música, da dança e do teatro, por que o grupo da época era formado só por educação artística, não tinha professor de música... Acho que essa foi a referência da construção e óbvio que as nossas práticas vivenciadas por que, como é que a gente aprendeu história da arte na faculdade? Eu aprendi dessa maneira, acho que você também, a maioria teve uma história da arte linear! [...] a PCNP que já é aposentada, tinha um viés muito forte com a Abordagem Triangular, a necessidade da apreciação, da 
contextualização e da produção sempre caminhou muito junto até por que ela tinha esse olhar... E isso em 2004, 2005, 2006 [...] a gente foi seguindo esse rumo, com adaptações por que tinham alguns projetos descentralizados que vinham da antiga CENP [...] "O corpo e suas representações." [...] "Projeto Coca-Cola" [...], "Lá vai Maria" [...], "Arte BR" [...], teve uns anos que veio a questão do cinema [...] do filme do minuto que era bacana também [...], mas o 'feijão com arroz' era esse currículo que a gente tinha elaborado pensando nas nossas escolas, na nossa Diretoria e que foi se transformando no contexto de cada um [...], havia uma preocupação, havia um norte nesse caminho, isso antes do Currículo do Estado. (Professora CMA)

É perceptível a presença de concepções históricas de ensino de arte no Brasil através das falas dessas/os professoras/es, assim como é perceptível que o envolvimento com o Currículo demanda uma negociação entre concepções préexistentes e concepções curriculares. Em nossos discursos e/ou práticas coexistem harmoniosa ou conflituosamente concepções de ensino da arte como expressão, cultura, técnica e/ou linguagem, polivalência, história da arte, cultura visual, leitura de imagem/obra de arte, arte contemporânea... As/os professoras/es me disseram: "A gente não sabe o que fazer..."; "Nosso conhecimento é fragmentado..."; "Eu não tenho segurança nas outras linguagens..."; "Tem partitura no Currículo, aquilo para mim é grego!". E eu me pergunto: políticas públicas podem, devem e/ou desejam se comprometer com as transformações em nossas concepções?

\section{Concepções de currículo de Arte}

[...] a gente fazia muita coisa, só que eu não seguia currículo nenhum, seguia os livros que eram resquícios de apostila, livro didático de arte que iam para as escolas particulares como propaganda das editoras, a escola vê o que acha mais interessante, mas sem base em currículo nenhum... [...] a escola não adotava, eu recebia e seguia aquele que achava mais interessante, mas nunca nem pensei em currículo nenhum, achava que o que tinha ali era aquilo! [...] eu nunca gostei de ficar fechada numa coisa só [...] a forma de apresentar que parece um tanto confusa [...]a ideia de território, não tem essa coisa de habilidades e competências, o que você quer com aquilo? Eu acho um pouco confuso! [...] eu vejo tanta barbaridade por aí, eu posso até estar fazendo barbaridade - quem sou eu pra dizer - posso estar equivocada, mas eu vejo muita coisa que eu prefiro não ver... depende do professor [...] não sei o que seria pior! [...] O problema está na formação... O comprometimento seria a palavra... Acho que tem mais questão ética e moral aí... (Professora PIE)

[...] antigamente eu acho que eu entendia o currículo como o rol dos conteúdos, única e exclusivamente, então, se você me perguntasse a alguns anos atrás, talvez eu te respondesse assim [...] Currículo é o rol dos conteúdos que têm que ser trabalhados no semestre, no bimestre no ano letivo. E hoje eu tenho certeza que eu compreendo currículo como uma trama de relações. Que tem conteúdo? Tem, claro que tem! A gente não pode esquecer do que se fala, mas tem sobre o como se fala, com o que se fala, com quem se fala, então, eu penso no currículo de uma maneira muito mais ampla por que ele tece as minhas relações formativas com o material, com os meus alunos e dos alunos comigo e com os pais, de como a escola compreende a educação, qual é o perfil que a gente tem e que a escola também muda, a gente tem que dizer isso, a escola é muito parceira nessas mudanças de olhares por que a gente comunga de um pensar a educação, a gente não está aqui, cada um entra na sua aula de 
cinquenta minutos e vai embora! Todo mundo pensa a educação de uma maneira e que é uma maneira que talvez não seja em outro lugar, e outro lugar e outro lugar! Por que é característica daqui, desse grupo que se constitui, então, eu acho que o currículo para mim hoje - eu não penso em uma definição fechada, mas se eu pudesse tentar colocar em palavras - eu acho que ele é um feixe de relações, o currículo é um feixe de relações! De relações que tem que ver com concepções de ensino, com concepções de aprendizagem, que tem a ver com parcerias, com partilhas, que tem a ver com conteúdo, que tem a ver com afeto, que tem a ver com o outro, eu acho que é por aí! E mudou muito! (Professora CMA)

Todo/a professor/a tem uma noção do que seja um currículo, mesmo sem saber disso e mesmo que não faça uso dessa palavra para designá-lo, mesmo que seja a simples noção de rol de conteúdos ou de que currículo é tudo que acontece na escola. Dos conteúdos, objetivos, metodologias e avaliações até as relações hierárquicas e/ou afetivas que ali se constroem, a noção de currículo passa também pela maneira como cada sujeito lida culturalmente com o processo de ensino/aprendizagem, com o projeto arquitetônico, com a disposição do mobiliário em sala de aula, com a merenda, com as grades, muros e uniformes, com a ocupação da escola pelas/os estudantes em protesto, com a presença ofensiva da polícia para reprimir o protesto, bem como, com o diálogo e mesmo a falta ou a impossibilidade dele junto às/aos gestoras/es e aos seus pares... No entanto, temos conversado sobre essas questões na escola ou nas diretorias de ensino? Ouçamos:

[...] as versões, as formas como isso chegou para nós foram de todas: "você tem que...", "Você pode que...." Foram de várias maneiras [...] nunca definitivo! Não houve assim, "Olha, vamos fazer isso...", não houve um momento de refletir sobre isso, esses momentos, eles acontecem no seu isolamento, na sua preparação de aula, não houve... Foram de várias formas, por exemplo, essa escola mesmo eu tive um coordenador que falou "Poxa, você não trabalha o Currículo do Estado, como é que fica isso? Como é que fica esse aluno se vier transferido, se for transferido, como é que você lidará com isso já que há uma proposta unificada?". Então, nós temos essas cobranças e aí, como é que depois efetivamente isso foi cobrado? Nas avaliações de mérito! [...] "Olha, tudo bem, você faz como você quiser, mas eu vou te cobrar na avaliação de mérito!". Então, é uma forma assim, eu diria até um tanto maquiavélica por que você não convenceu, você não ofereceu pertencimento do currículo, da proposta ao professor, depois você cobra o professor nessas avaliações, então, isso daí eu achei muito danado! (Professor SBR)

Gostaria de encerrar este texto citando uma pesquisa realizada pela professora Géssica Priscila Ramos - UFSCar/SP. Segundo a autora, em consonância com transformações educacionais na esfera global e nacional, a partir da década de 1990, o Estado de São Paulo deu início a um conjunto de reformas alinhadas ao ideário político neoliberal, caracterizado pela "hipervalorização das noções de qualificação e de competência, ao trazer como pressuposto a ideia de que a melhoria e a qualificação 
do processo produtivo não seriam possíveis em locais com deficiências educacionais..." (RAMOS, 2013, p. 540).

O Currículo de Arte de São Paulo é parte de um conjunto de medidas dessas políticas neoliberais e a despeito de ter sido imposto e não proposto à rede pública, é um currículo condizente com paradigmas de ensino/aprendizagem da arte pósmodernos. No entanto, sua implantação não propiciou a cada professor/a construir o que aqui denominei de "intimidade com suas concepções formativas".

Políticas públicas podem viabilizar a construção de intimidade, pertencimento e autonomia nas concepções formativas docentes. Políticas partidárias momentâneas carecem desse compromisso.

De fato, “...nada de novo há no rugir das tempestades.”

\section{Referências}

ARROYO, Miguel G. Currículo, território em disputa. 2. ed. Petrópolis/RJ: Vozes, 2011.

BARBOSA, Ana Mae. Tópicos Utópicos. Belo Horizonte/MG: Editora C/ Arte, 1998.

BARBOSA, Ana Mae. Da interdisciplinaridade à interterritorialidade: caminhos ainda incertos. Paidéia: revista do curso de Pedagogia da FUMEC. Belo Horizonte/MG: Ano 7, n. 9, p. 11-29, jul./dez. 2010. Disponível em: http://www.fumec.br/revistas/paideia/article/view/1288 . Acesso em: 10 de jul. 2018.

BARBOSA, Ana Mae; COUTINHO, Rejane Galvão. Ensino da arte no Brasil: aspectos históricos e metodológicos. Rede São Paulo de Cursos de Especialização para o quadro do Magistério da SEESP - RedeFor - Ensino Fundamental II e Ensino Médio. Universidade Estadual Paulista - UNESP e Secretaria de Estado da Educação de São Paulo - SEE/SP, Coordenadoria de Estudos e Normas Pedagógicas. São Paulo: 2011. Disponível em: https://acervodigital.unesp.br/bitstream/ 123456789/40427/3/2ed_art_m1d2.pdf. Acesso em: 10 de jul. 2018.

LOPES, Alice C.; MACEDO, Elizabeth. Teorias de currículo. São Paulo/SP: Cortez, 2011.

RAMOS, Géssica Priscila. A política educacional paulista (1995-2010) e seus impactos na identidade da escola e do professor. In: Revista Brasileira de Política e Administração da Educação (ANPAE: Associação Nacional de Política e Administração da Educação), v. 29, n. 3, p. 537-556, set./dez. 2013. Disponível em: http://seer.ufrgs.br/rbpae/article/view/47224/29425 . Acesso em: 10 de jul. 2018.

SÃO PAULO, Secretaria da Educação do Estado de São Paulo. Currículo do Estado de São Paulo. Coord. Maria Inês Fini. São Paulo: SEE, 2010.

SILVA, Tomaz Tadeu da. Documentos de identidade: uma introdução às teorias do currículo. 3. ed. 3. reimp. Belo Horizonte/MG: Autêntica, 2011. 


\section{Maristela Sanches Rodrigues}

Professora de Arte no Instituto Federal de São Paulo (IFSP — campus Jacareí). Doutora em Artes pelo Instituto de Artes da Universidade Estadual Paulista Júlio de Mesquita Filho (UNESP). Pesquisas nas seguintes áreas: ensino/aprendizagem de arte; formação de professores de arte; currículo de arte; teoria do desenvolvimento estético; mediação cultural; desenho e plástica.

E-mail: maristelasr@uol.com.br

Currículo: http://lattes.cnpq.br/2455707598788562

Recebido em 30 de maio de 2018 Aceito em 15 de agosto de 2018 